\title{
Temper Embrittlement and Pine Cone Like Fracture Surface of $5.5 \%$ Ni Cryogenic Steels ${ }^{*}$
}

\author{
By Masato MURAKAMI,** Kōji SHIBATA,** Kotobu NAGAI*** \\ and Toshio FUJITA**
}

\begin{abstract}
Synopsis
Pine cone like fracture surface ("pine cone") is observed in some ferritic steels containing retained austenite when temper embrittled. Microscopic observations and various mechanical tests are performed to elucidate the characteristics of this fracture surface by using $5.5 \% \mathrm{Ni}$ steels.

It is found that "pine cone" is the intergranular fracture surface produced by fracture along P-segregated martensite/austenite interfaces which form at prior austenitic grain boundaries and its pine cone like surface is caused by the reverted austenites at the grain boundaries.

Intercritical temper promotes austenite formation thereby enhances the irregularity of the grain boundary and reduces the fraction of intergranular fracture or "pine cone".

It is also found through Mössbauer spectroscopy that the retained austenite at the grain boundaries transforms to martensite during fracture.
\end{abstract}

\section{Introduction}

While commercial $9 \% \mathrm{Ni}$ steel has sufficient toughness for cryogenic service after a simple quench and temper treatment, ferritic $5.5 \% \mathrm{Ni}$ steels require more elaborate thermal treatment. The necessary treatment is an intercritical temper (designated as $\mathrm{L}$ treatment ${ }^{1)}$ ) between quench (Q) and temper $(\mathrm{T})$ treatment. The QLT treated $5.5 \%$ Ni steels exhibit good impact properties at $-196^{\circ} \mathrm{C}$. This is because the $\mathrm{L}$ treatment introduces a dense distribution of thermally stable precipitated austenite particles between martensite laths. ${ }^{1)}$

Ferritic steels have the high sensitivity to temper embrittlement, which is characterized by intergranular fracture. The effect of intercritical temper on intergranular fracture, however, has not been clarified and is of much interest because the austenite also precipitates at the grain boundaries.

The QT and QLT treated $5.5 \% \mathrm{Ni}$ steels exhibit the fracture mode which looks like a pine cone when temper embrittled by slow cooling from the final temper or by reheating in the temperature range of $400 \sim$ $500{ }^{\circ} \mathrm{C}$. This type of fracture surface is also observed in some other ferritic steels ${ }^{2}$ ) containing retained austenite $\left(\gamma_{R}\right)$ when temper embrittled and broken in a brittle manner. This implies that the fracture surface has a correlation with the $\gamma_{R}$ and temper embrittlement. Since few studies have been made of the fracture surface, it is named as "pine cone" and an investigation has been carried out to elucidate the characteristics of this fracture surface.

\section{Experimental}

The series of alloys, whose chemical compositions are given in Table 1, were prepared by vacuum melting using electrolytic iron and high purity alloy additions to produce $17 \mathrm{~kg}$ cast ingots. They were subsequently heated at $1200^{\circ} \mathrm{C}$, then forged and rolled to $13 \mathrm{~mm}$ diameter rods for tensile test specimens and to $16 \mathrm{~mm}$ thick plates for Charpy and compact tension test specimens.

The heat treatments employed are described schematically in Fig. 1. Austenitization and tempering were carried out in an argon atmosphere tube furnace.

Impact properties at $-196^{\circ} \mathrm{C}$ were obtained through standard Charpy $\mathrm{V}$-notch impact tests and the resulting fracture surfaces were observed by using
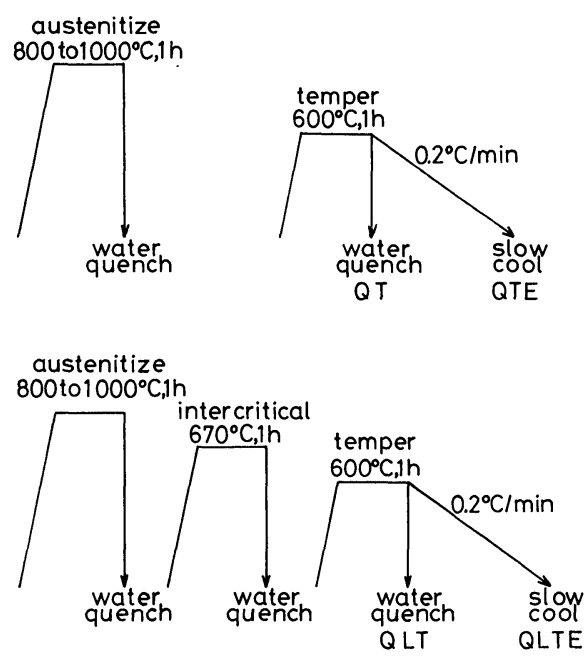

Fig. 1. Schematic representation for heat treatments.

Table 1. Chemical compositions. (wt \%)

\begin{tabular}{l|ccccccccc} 
& $\mathrm{C}$ & $\mathrm{Si}$ & $\mathrm{Mn}$ & $\mathrm{P}$ & $\mathrm{S}$ & $\mathrm{Ni}$ & $\mathrm{Cr}$ & $\mathrm{Mo}$ & $\mathrm{Fe}$ \\
\hline M0 & 0.060 & 0.28 & 1.20 & 0.006 & 0.002 & 5.84 & 0.65 & 0.21 & bal. \\
M1 & 0.070 & 0.28 & 1.20 & 0.003 & 0.007 & 5.64 & 0.64 & nil. & bal. \\
M2 & 0.060 & 0.29 & 1.19 & 0.003 & 0.005 & 5.87 & nil. & nil. & bal.
\end{tabular}

* Originally published in Tetsu-to-Hagané, 69 (1983), 806, in Japanese; Formerly presented to the 100th ISIJ Meeting, October 1980, S1065, at Kyushu University in Fukuoka. English version received October 22, 1982. (C) 1983 ISIJ

** Department of Material Science, Faculty of Engineering, The University of Tokyo, Hongo, Bunkyo-ku, Tokyo 113.

*** Tsukuba Laboratories, National Research Institute for Metals, Sakura-mura, Niihari-gun, Ibaraki 305. 
a scanning electron microscope.

$\mathrm{X}$-ray diffraction was used to determine the fraction of retained austenite in the manner as Miller proposed. ${ }^{3)}$

Mössbauer effect scattering was used to determine the austenite concentration on the fracture surfaces by detecting back-scattered conversion electrons. The observed spectrum was free from the influence of texture, surface roughness, and the deformation present. This technique has been proved effective in austenite/ martensite analysis. ${ }^{4-6}$ )

Auger electron spectroscopy (AES) was used to detect the segregation of impurities by using a $5 \mathrm{~mm}$ diameter cylindrical specimen with $60 \mathrm{deg}$ angle notch.

Fracture toughness $\left(K_{\text {IC }}\right)$ at $-196^{\circ} \mathrm{C}$ was obtained through compact tension tests with the specimens designed to satisfy the ASTM standard E-399.7)

Microstructures were observed through a transmission electron microscope using thin films, two stage replicas, and carbon extracted replicas. ${ }^{8)}$

Optical metallography was facilitated by use of a $2 \%$ nitric alcohol and a saturated solution of picric acid in $100 \mathrm{~m} l$ water with $1 \mathrm{~g}$ sodium tridecylbenzene sulfonate added as a wetting reagent. ${ }^{9)}$ The latter etchant was used to reveal phosphorus segregation to grain boundaries.

\section{Results and Discussion}

\section{1. "Pine Cone" and Fracture Toughness}

The QLT treated steels M1 and M2 had good impact properties at $-196^{\circ} \mathrm{C}$ and exhibited ductile fracture mode. These steels were embrittled when slow cooled at the rate of $0.2{ }^{\circ} \mathrm{C} / \mathrm{min}$ from $600{ }^{\circ} \mathrm{C}$ and exhibited a mixed mode of "pine cone" and quasicleavage. The observation was made on the "pine cone" facet through a scanning electron microscope as shown in Photo. 1(a) and also with two stage replica through a transmission electron microscope as presented in Photo. 1(b).

Compact tension tests were conducted with QLT $\mathrm{MO}, \mathrm{QLT}^{\prime}\left(500^{\circ} \mathrm{C}\right) \mathrm{M} 1$, and QLTE $\mathrm{Ml}$ in a liquid nitrogen bath and the resulting fracture surfaces were mainly composed of dimple, quasi-cleavage, and " pine cone", respectively. The typical results along with the Charpy impact test results are given in Table 2. The specimen exhibiting the "pine cone" fracture mode had the lowest fracture toughness when assessed by both crack opening displacement and fracture toughness.*

\section{The Crack Path of "Pine Cone"}

The crack path of "pine cone" was examined in the compact tension test specimen of QLTE treated $\mathrm{Fe}-5.5 \mathrm{Ni}-0.6 \mathrm{Cr}$ alloy $(\mathrm{M} 1)$ which exhibited the brittle fracture mode composed of quasi-cleavage and " pine cone". The cross section of the cracked specimen was revealed by using $2 \%$ nital and the crack path was found to be both intergranular and transgranular.

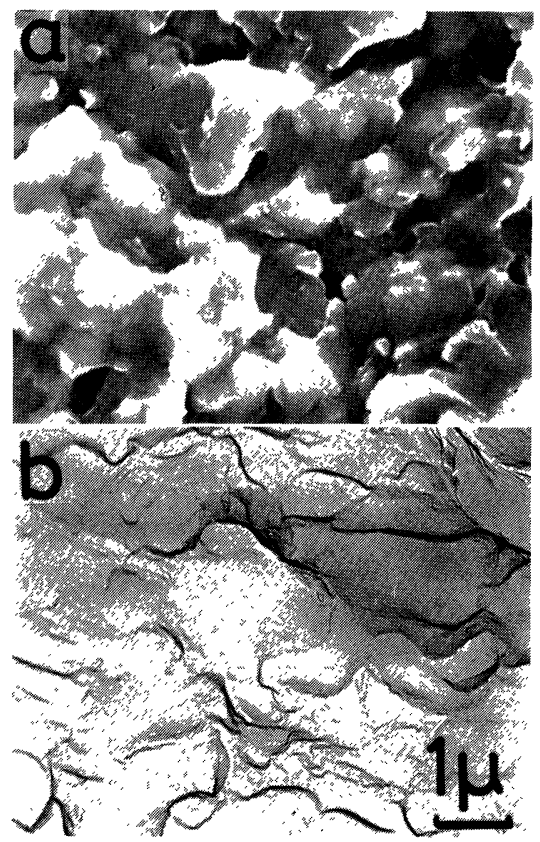

Photo. 1. Scanning electron fractograph (a), and transmission electron micrograph of two stage replica (b) of " pine cone" of M2.

Table 2. Results of compact tension and Charpy impact tests at $-196^{\circ} \mathrm{C}$.

\begin{tabular}{l|ccccc}
\hline Specimen & $\begin{array}{c}\text { Fracture } \\
\text { surface*1 }\end{array}$ & $\begin{array}{c}C T O D^{* 2} \\
(\mathrm{~mm})\end{array}$ & $\begin{array}{c}K_{Q}^{* 3} \\
\left(\mathrm{kgf} / \mathrm{mm}^{3 / 2}\right)\end{array}$ & $\begin{array}{c}v E \\
(\mathrm{kgf}-\mathrm{m})\end{array}$ \\
\hline QLT $\mathrm{M} 0$ & $D+C$ & 0.165 & 864 & 30.0 \\
$\mathrm{QLT}^{\prime} \mathrm{M} 1$ & $G$ & 0.074 & 335 & 5.6 \\
QLTE M1 & $P$ & 0.020 & $172^{*}$ & 1.7 \\
\hline
\end{tabular}

*1 $D$ : Dimple, $C$ : Cleavage, $P$ : Pine cone

*2 $C T O D=C O D / 1+((a+z) / r(w-a))$

$a$ : Crack length, $z:$ Knife edge width, $r:$ Rotational factor *3 QLTE M1* only meets the plane strain condition: $B \geq$ $2.5\left(K_{\mathrm{IC}} / \sigma_{y}\right)^{2}$

$B$ : Specimen width, $\sigma_{y}$ : Yield strength

A further investigation was made on the crack whose inside surface was observable through a scanning electron microscope. It is demonstrated as shown in Photo. 2 that intergranular and transgranular cracks correspond to "pine cone" and quasi-cleavage, respectively. There are, however, various kinds of boundaries which can be paths for fracture and it seems difficult to define which boundary corresponds to the crack path by observing the cross section alone. Since "pine cone" seems to have a correlation with temper embrittlement and prior austenitic grain boundaries are most susceptible to the temper embrittlement, comparison was made between the prior austenite grain size and the "pine cone" facet sizes in the QTE and QLTE treated steel M2. Malm and Norström ${ }^{10}$ ) have shown that fracture surfaces can be used for determination of grain size. So scanning electron and optical micrographs were used to measure the sizes of fracture surface facets and the prior austenite grains, respectively. Histograms were then

* In this case only the QLTE M1 satisfied the palne strain conditions and yielded valid $K_{\mathrm{IC}}$. 


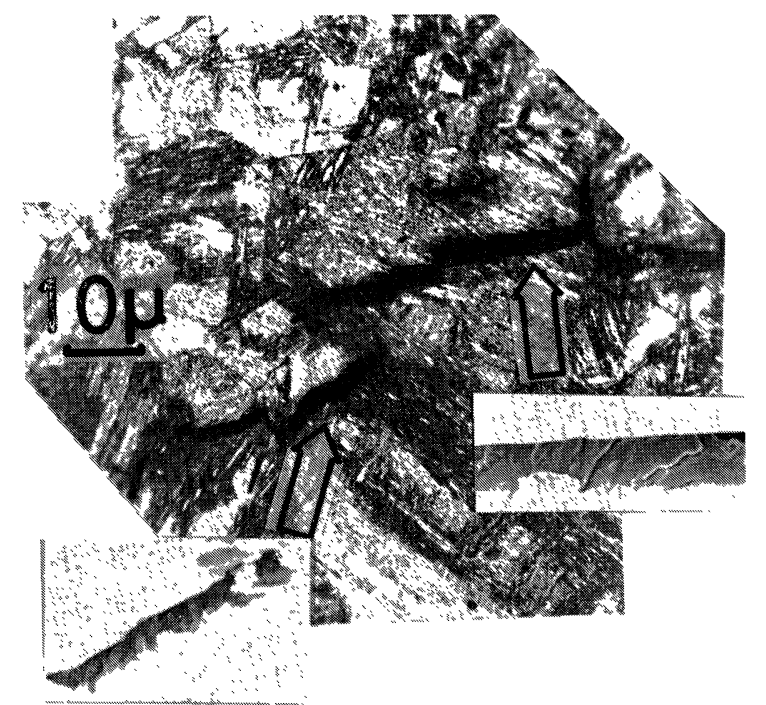

Photo. 2. Optical micrograph of the crack introduced to compact tension specimen of M1. Corresponding fracture surfaces are also observed through scanning electron microscope. Note intergranular and transgranular cracks correspond to " pine cone" and cleavage, respectively. (SEM at $\times 2000)$

made from the measured values and shown in Fig. 2. A good correlation between the " pine cone" facet size of the QTE specimen and the prior austenite grain size was confirmed, where the fracture path of "pine cone" was considered to be along the prior austenitic grain boundaries. Meanwhile, the QLTE treated specimen had rather small " pine cone "facet size compared with the prior austenite grain size. This will be discussed in Section III.4.2.

\section{Temper Embrittlement}

It is well known that temper embrittlement is associated with impurity segregation which reduces the cohesive strength of grain boundary and thereby causes intergranular fracture. ${ }^{11)}$ Therefore, the impurity segregation on "pine cone" was examined by AES. Since the specimen for AES analysis is small and brittle fracture is unlikely to occur compared with Charpy and compact tension tests, a relatively high austenitizing temperature of $1200^{\circ} \mathrm{C}$ was employed to obtain brittle fracture. "Pine cone" of $\mathrm{Q}$ $\left(1200{ }^{\circ} \mathrm{C}\right)$ LTE treated M1 exposed by in-situ fracture was detected through AES and the spectrum as shown in Fig. 3(a) was obtained, showing the presence of phosphorus on the "pine cone". The $\mathrm{P}$ peak disappeared by sputtering the fracture surface for some time using $\mathrm{Ar}^{+}$ion, indicating that the phosphorus existed as a segregant (Fig. 3(b)). A two step temper embrittlement is characterized by its reversibility, that is, toughness can be restored by heating for very short time at temperatures of approximately $600{ }^{\circ} \mathrm{C}$ and higher. Slow-cooled or embrittled Fe-5.5Ni$0.6 \mathrm{Cr}$ alloy (M2) was tempered at $600^{\circ} \mathrm{C}$ for $10 \mathrm{~min}$ (de-embrittlement treatment) and then subjected to Charpy impact test at $-196^{\circ} \mathrm{C}$. No "pine cone" but dimple and quasi-cleavage were observed in the fracture surface. When this specimen was slow-cool-

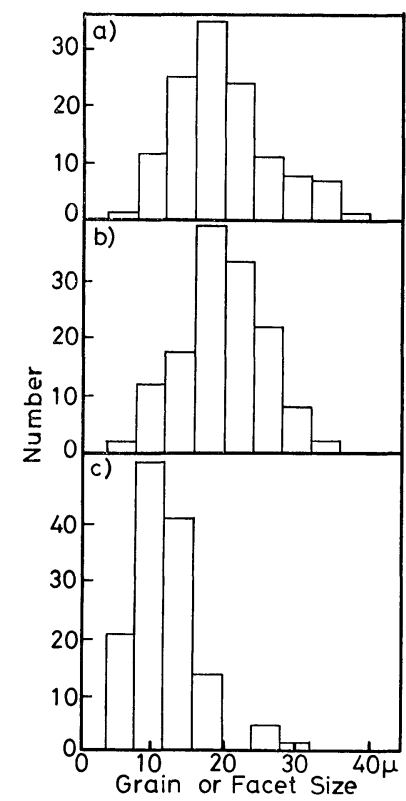

Fig. 2. Histograms showing the distribution of prior austenite grain sizes of M2 (a) and "pine cone" facet sizes of QTE M2 (b) and QLTE M2 (c).

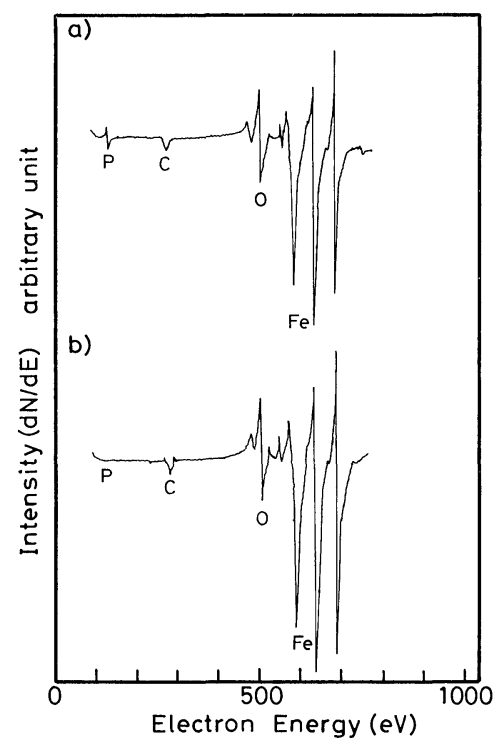

(a) Fresh fracture surface

(b) After $\mathrm{Ar}^{+}$sputtering for $30 \mathrm{sec}$

Fig. 3. Auger electron spectra from "pine cone" of $Q$ $\left(1200^{\circ} \mathrm{C}\right)$ LTE M1.

ed again at the rate of $0.2{ }^{\circ} \mathrm{C} / \mathrm{min}$ from $600^{\circ} \mathrm{C}$, " pine cone " appeared again, which is consistent with the reversibility of the temper embrittlement (Photo. $3)$.

\section{Influence of Heat Treatment}

\section{Q Treatment}

The typical properties of M2 when the quenching temperatures are varied from 800 to $1000^{\circ} \mathrm{C}$ are given in Table 3. The surface roughness of "pine cone" increased with decreasing $Q$ temperature, which corresponded to an increase in the amount of $\gamma_{R}$. However, impact energies were little affected by 


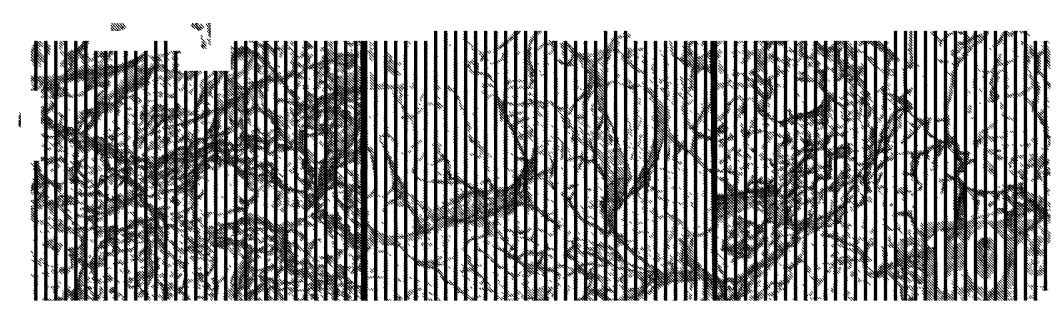

Photo. 3. Scanning electron fractographs of M2: (a) QLTE treated; (b) reheated at $600{ }^{\circ} \mathrm{C}$ for $1 \mathrm{~h}$ after QLTE treated. Note no "pine cone" is observed in the fracture surface. (c) Embrittled by slow cooling at the rate of $0.2^{\circ} \mathrm{C} / \mathrm{min}$ after QLTE $+\mathrm{DE}$ treated. Note "pine cone" appeared again in the fracture surface.

Photo. 4.

Scanning electron micrographs of microstructures of $\mathrm{M} 2: \quad$ (a) $\mathrm{Q}\left(1000^{\circ} \mathrm{C}\right) \mathrm{TE}$ treated; (b) $\mathrm{Q}\left(1000^{\circ} \mathrm{C}\right)$ $\mathrm{L}\left(700^{\circ} \mathrm{C}\right) \mathrm{TE}$ treated, and corresponding fracture surfaces: (c) QTE; (d) QLTE.

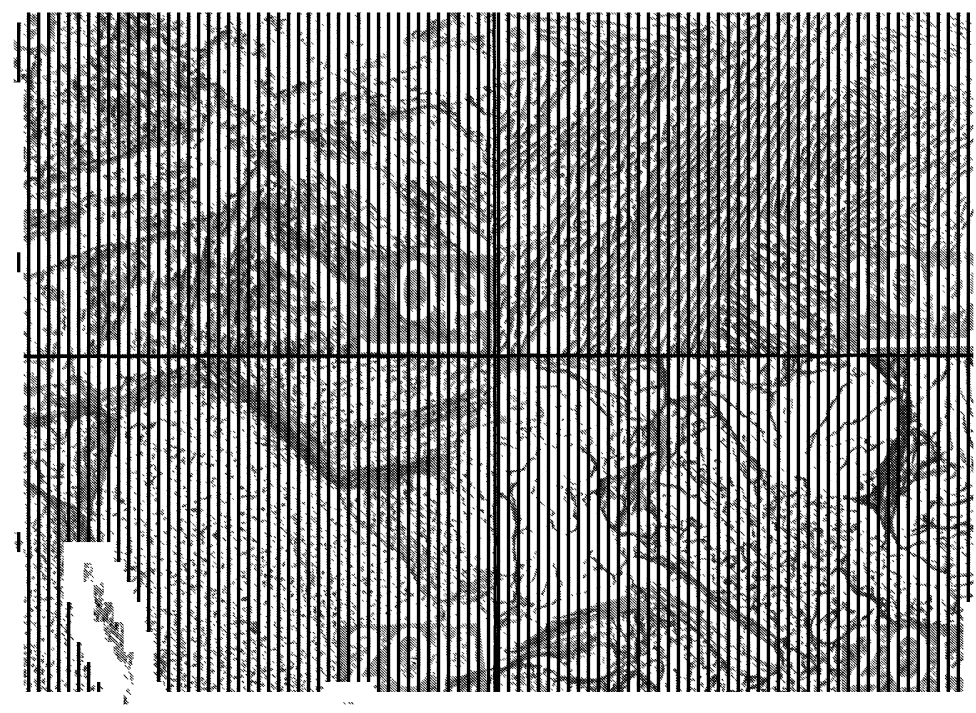

Table 3. Effects of $Q$ temperature and $\mathrm{L}$ treatment on the amount of retained austenite $\left(\gamma_{R}\right)$, Charpy impact energy $(v E)$, and tensile properties at $-196^{\circ} \mathrm{C}$.

\begin{tabular}{c|cccc|cccc}
\hline Q temp. & \multicolumn{9}{|c|}{ QTE } & \multicolumn{3}{c}{ QLTE } \\
\hline$\left({ }^{\circ} \mathrm{C}\right)$ & $\begin{array}{c}\gamma_{R} \\
(\%)\end{array}$ & $\begin{array}{c}v E \\
(\mathrm{kgf}-\mathrm{m})\end{array}$ & $\begin{array}{c}\sigma_{l y} \\
\left(\mathrm{kgf} / \mathrm{mm}^{2}\right)\end{array}$ & $\begin{array}{c}\sigma_{u} \\
\left(\mathrm{kgf} / \mathrm{mm}^{2}\right)\end{array}$ & $\begin{array}{c}\gamma_{R} \\
(\%)\end{array}$ & $\begin{array}{c}v E \\
(\mathrm{kgf}-\mathrm{m})\end{array}$ & $\begin{array}{c}\sigma_{l_{y}} \\
\left(\mathrm{kgf} / \mathrm{mm}^{2}\right)\end{array}$ & $\begin{array}{c}\sigma_{u} \\
\left(\mathrm{kgf} / \mathrm{mm}^{2}\right)\end{array}$ \\
\hline 1000 & 1.0 & 0.0 & 84.7 & 100.0 & 3.0 & 1.7 & 82.4 & 97.7 \\
900 & 2.6 & 0.1 & 87.2 & 102.4 & 4.0 & 3.2 & 86.0 & 102.2 \\
850 & 2.9 & 0.1 & 92.0 & 102.0 & 5.5 & 1.7 & 91.2 & 100.9 \\
800 & 3.0 & 0.1 & 92.9 & 102.8 & 6.0 & 2.4 & 92.4 & 102.8 \\
\hline
\end{tabular}

$\sigma_{l y}:$ Lower yield strength

$\sigma_{u}:$ Ultimate tensile strength

the $Q$ temperature in both the QTE and QLTE conditions. This may be explained by that decreasing the $Q$ temperature also increases the yield strength and will reduce the toughness, whereby the impact energies do not increase with the increase of the $\gamma_{R}$ amount.

\section{Intercritical Heat Treatment (L Treatment)}

Intercritical heat treatment affects the microstructure hence the fracture behavior. The microstructures and the fracture surfaces of the QTE and QLTE treated M2 (Q: $1000{ }^{\circ} \mathrm{C}$ ) are shown in Photo. 4. The amount of reverted austenite at the prior austenitic grain boundaries of the QTE M2 was small and its fracture surface was not so rough and appeared to be a typical intergranular fracture surface, while the microstructure of the QLTE M2 was composed of a large quantity of closely packed austenites (partly transformed to fresh martensites) and the corresponding fracture surface comprised a mixture of "pine cone" and quasi-cleavage. This shows that the L treatment increased the fraction of quasi-cleavage. To explain this, two sources are considered: a decrease in the cleavage strength; and an increase in the cohesive strength of the grain boundaries.

The second particle such as precipitate will reduce the cleavage strength. According to the transmission electron microscopic observation of extraction replicas and thin films no distinguishable difference existed in the amount, size, and distribution of precipitates (carbides) between the QTE and QLTE specimens. Furthermore the L treatment introduces thermally stable austenites into the structure and makes the cleavage fracture difficult. ${ }^{1)}$ Consequently the increase in the fraction of quasi-cleavage cannot 
be attributed to the decrease in the cleavage strength.

Since austenite reverts along laths and grain boundaries in a large amount during the intercritical temper and covers the prior austenitic grain boundaries which are most susceptible to temper embrittlement, the resistance of the grain boundaries to the temper embrittlement will be enhanced and thereby the fraction of "pine cone" is reduced.

The QT specimen with the insufficient amount of austenite was embrittled severely and the fracture occurred along the grain boundaries as indicated in Fig. 4(a), while the QLTE treated specimen with a large quantity of austenite was not so susceptible to the temper embrittlement and the fracture was both intergranular and transgranular (Fig. 4(b)). As can be seen in Fig. 4 this causes the "pine cone" facet size of the intercritically tempered specimen smaller than the prior austenite grain size as mentioned before.

Wada et al. ${ }^{12,13)}$ and Ucisik et al. ${ }^{14)}$ also investigated the effect of intercritical heat treatment on temper embrittlement. In their case, however, the intercritical temperatures were close to $A_{c 3}$ points and the grain refinement by recrystallization was utilized to suppress the temper embrittlement. So the mechanism in suppressing the temper embrittlement is different from that in the present investigation.

\section{Surface Roughness of "Pine Cone"}

The fracture path when " pine cone" was produced, was found to be along the prior austenitic grain boundaries which contained a large quantity of reverted austenite. Hence three possible cases exist for the fracture:

(a) inside the reverted austenite,

(b) along precipitate/martensite matrix interfaces, and

(c) along austenite/martensite matrix interfaces.

The first case is unlikely to occur since the $\mathrm{P}$ segregation was found on "pine cone" and can hardly take place inside the austenite phase. Case (b) is not directly related to the austenite. However, a pine cone like appearance may be produced by fracture along the precipitate/martensite matrix interfaces, if the impurity segregation occurs at these interfaces. ${ }^{15}$ ) In order to examine this, the extraction replicas ${ }^{8)}$ taken from the " pine cone" facets were observed. As shown in Photo. 5(a) fine precipitates determined as $\mathrm{M}_{7} \mathrm{C}_{3}$ through electron diffraction existed on the " pine cone" of $\mathrm{Ml}$, while no precipitate was observed in the case of M2 as shown in Photo. 5(b), indicat-

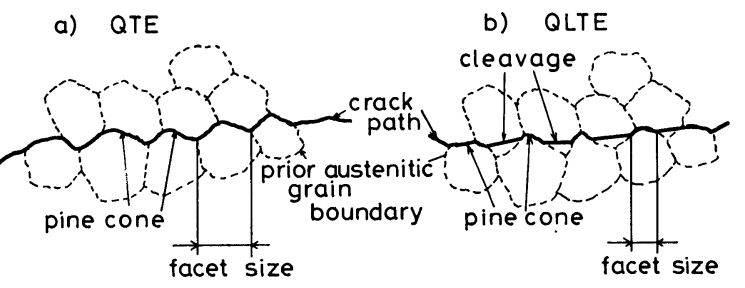

(a) QTE (b) QLTE

Fig. 4. Schematic illustration for crack path. ing that the surface roughness is not due to the precipitates.

Fe-5.5Ni-0Mo alloy (M2) quenched from $1000{ }^{\circ} \mathrm{G}$ was intercritically heated at $670^{\circ} \mathrm{C}$ for $5 \mathrm{~h}$ to promote the formation of austenite at the grain boundaries followed by temper at $600{ }^{\circ} \mathrm{C}$ and slow cooling. The microstructure was revealed by the special etchant which preferentially attacks P-containing grain boundaries and is shown in Photo. 6. The grooves formed by etching are observed at the martensite/austenite $\left(\alpha^{\prime} / \gamma\right)$ interfaces showing the P segregation, the degree of which varies from one interface to another. Ogura et al. ${ }^{16)}$ showed that incoherent interfaces absorbed $\mathrm{P}$ but not coherent ones and coherency was considered to play a key role in the observed phenomenon. Smith $^{17)}$ suggested that a crystal of proeutectoid ferrite, formed at grain boundary between two grains of austenite, would have a definite orientation relationship to one of them, resulting in a partial coherent interface. Smith's hypothesis has not been confirmed by an experiment, but is consistent with the observa-

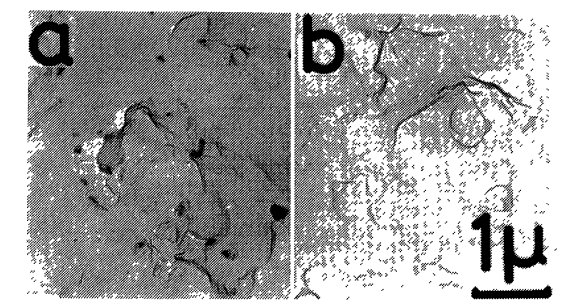

Photo. 5. Extraction replicas taken from " pine cone" fracture surfaces of M1 (a) and M2 (b).

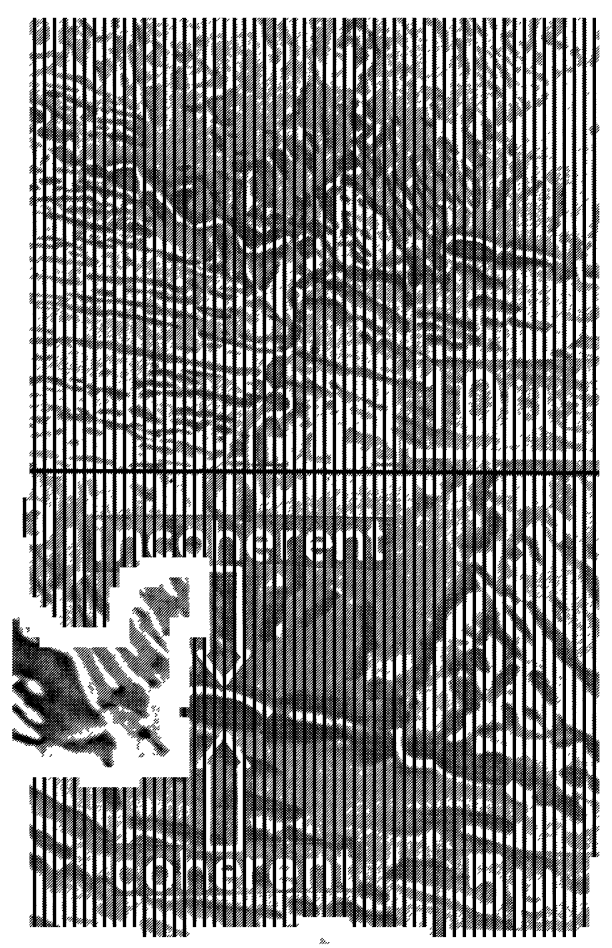

Photo. 6. Scanning electron micrographs showing microstructure of $Q\left(1000^{\circ} \mathrm{C}\right) \mathrm{L}\left(670^{\circ} \mathrm{C} \times 5 \mathrm{~h}\right)$ TE M1 revealed by a special etchant which preferentially attacks P-containing boundary. 
tion made by Honeycombe and Pickering. ${ }^{18)}$ In the present investigation, the mechanism of austenite reversion at the grain boundaries, and the coherency and the orientation relationship of the interfaces were not obtained. However, it can be implied that the austenite reverted at the grain boundaries as Smith suggested and the $\mathrm{P}$ segregation occurred at the incoherent interfaces. Then "pine cone" can be considered to be produced by the crack propagation along the P-segregated $\alpha^{\prime} / \gamma$ interfaces.

The austenite reverted at grain boundaries can affect the toughness. If the grain boundaries are covered with the austenite as shown in Photo. 6, $\alpha^{\prime} / \gamma$ interfaces become new segregation sites for impurities. In such a case the surface area for segregation will increase* and thus the degree of the segregation will decrease and the crack path becomes rough so that the resistance to crack propagation increases. This implies that the rougher the interfaces are, the more resistance to the temper embrittlement can be achieved.

\section{The Stability of Retained Austenite}

Many works have been made on the effect of $\gamma_{R}$ on the low temperature toughness. ${ }^{19)}$ In general $\gamma_{R}$ which transforms easily to martensite due to sub-zero treatment and/or deformation is believed to deteriorate the low temperature toughness since the brittle martensite phase becomes preferential crack nucleation site and gives a preferred path for cleavage fracture. ${ }^{20}$ ) However, the effect of $\gamma_{R}$ on intergranular fracture is uncertain.

Mössbauer analysis was carried out to determine the stability of $\gamma_{R}$ by comparing the amount of $\gamma_{R}$ on "pine cone" with that in the bulk. The spectrum as in Fig. 5(a) was obtained and the austenite peak was absent. No austenite was detected on the surface electrolytically polished by $\sim 75 \mu \mathrm{m}$ from the fresh fracture surface as presented in Fig. 5(b). This indicates that the retained austenite transformed to martensite at least to $\sim 75 \mu \mathrm{m}$ below the fracture surface. For reference the radius of the plastic zone $\left(R_{p}\right)$ was estimated from the fracture toughness $\left(K_{\text {IC }}\right)$ of the QLTE treated Ml, according to the equation:

$$
R_{p}=(1 /(4 \sqrt{2} \pi)) \cdot\left(K_{\mathrm{IC}} / \sigma_{y}\right)^{221)}
$$

Substituting $K_{\mathrm{IC}}=172\left(\mathrm{kgf} / \mathrm{mm}^{3 / 2}\right)$ and $\sigma_{y}=90.2(\mathrm{kgf} /$ $\left.\mathrm{mm}^{2}\right)$ gives $R_{p} \simeq 205(\mu \mathrm{m})$. This suggests even the specimen with low absorbed energy has the plastic zone of a significant radius for this case and the retained austenite is thought to transform to martensite by the deformation due to the fracture.

The surface saw cut at $5 \mathrm{~mm}$ from the fresh fracture surface was analyzed by Mössbauer spectroscopy and the spectrum showed the clear austenite peak as shown in Fig. 5(c) corresponding to a retained austenite content of $7.5 \%$ by volume, which was compatible with the result from the X-ray analysis of $7.0 \%$ within the experimental error.

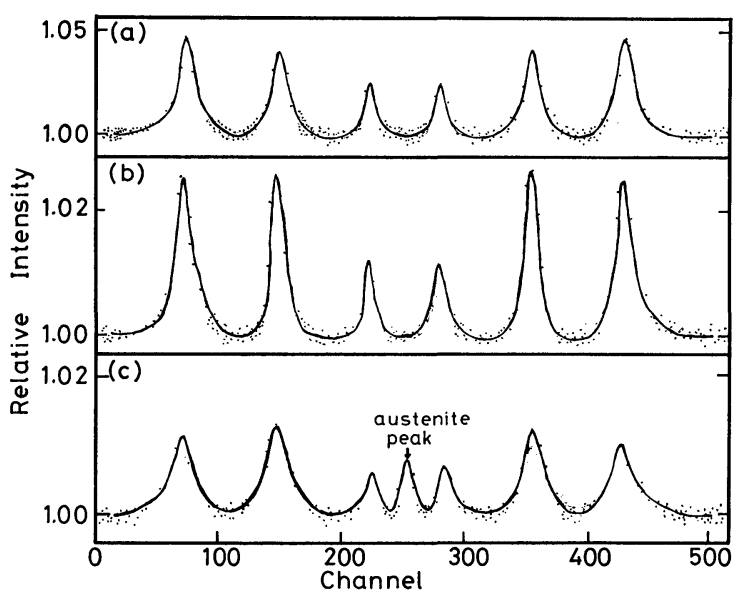

(a) Fresh fracture surface

(b) Fracture surface electropolished $\sim 75 \mu \mathrm{m}$

(c) The surface at $5 \mathrm{~mm}$ depth from the fresh fracture surface

Fig. 5. Conversion electron Mössbauer spectra from " pine cone" fracture surface of M1. Curves are handdrawn through datum points.

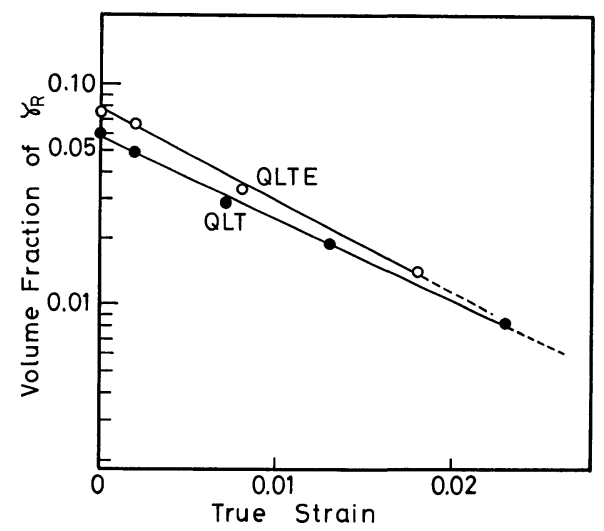

Fig. 6. Decomposition of retained austenite as a function of true strain.

Figure 6 shows variation in the amount of retained austenite of the QLT and QLTE treated M1 as a function of tensile strain. ${ }^{22)}$ The stability of $\gamma_{R}$ is relatively low compared with other metastable austenitic steels $^{23)}$ and the embrittling treatment did not appreciably affect the stability. Since the $\gamma_{R}$ transforms to martensite at a fairly low strain level, the retained austenite at the grain boundaries is considered to transform to martensite easily within the plastic zone associated with the fracture at $-196^{\circ} \mathrm{C}$.

\section{Conclusions}

Some ferritic steels containing retained austenite $\left(\gamma_{R}\right)$ exhibit pine cone like fracture surface (" pine cone") when temper embrittled. This suggests the temper embrittlement and the $\gamma_{R}$ have a correlation with "pine cone". Experiments have been conducted to elucidate the characteristics of this fracture surface by using $5.5 \% \mathrm{Ni}$ steels. The following conclu-

* Provided the austenite formed hemispherically with the radius of $r$, the surface area of a hemispherical $\alpha^{\prime} / \gamma$ interface is $2 \pi r^{2}$ and twice that of the prior austenitic grain boundary, $\pi r^{2}$. 
sions were obtained.

(1) "Pine cone" was found to be the intergranular fracture surface produced by the fracture along the P-segregated $\alpha^{\prime} / \gamma$ interfaces which formed at prior austenitic grain boundaries.

(2) The surface roughness of "pine cone" was due to the reverted austenite.

(3) The retained austenite present on the grain boundaries is considered to transform to martensite during fracture.

(4) Intercritical temper increased the amount of the reverted austenite or the roughness of the interfaces and thereby reduced the susceptibility to the temper embrittlement or the fraction of "pine cone" in the fracture surface.

\section{Acknowledgements}

The authors would like to thank Dr. R. Nakagawa of National Research Institute for Metals, Japan, for preparing the steels and Drs. S. Sekino and T. Inoue of Fundamental Research Laboratories of Nippon Steel Corporation for their useful discussion. They are also indebted to Prof. Y. Ishida and Dr. K. Sasa of the University of Tokyo for their help in Mössbauer analyses.

\section{REFERENCES}

1) S. Nagashima, T. Ooka, S. Sekino, H. Mimura, T. Fujima, S. Yano and H. Sakurai: Trans. ISIJ, 11 (1971), 402.

2) K. Nagai: Doctoral Thesis, The University of Tokyo, (1981).

3) R. L. Miller: Trans. ASM, 57 (1964), 892.

4) K. R. Swanson and J.J. Spikerman: J. Appl. Phys., 41
(1970), 3155.

5) D. J. Schwartzendruber and L. H. Benette: Script. Met., 6 (1972), 737.

6) N. Abe and L. H. Schwarts: Mat. Sci. Eng., 14 (1974), 239.

7) ASTM Standard E 399-74, Annual Book of ASTM Standards, (1974).

8) T. Akutagawa, I. Uchiyama and A. Fukami: Tetsu-toHagané, 43 (1957), 1222.

9) G. A. Dreyer, D. E. Austin and W. D. Smith: Metal Prog., 86 (1964), 116.

10) S. Malm and L. Norström: Scand. J. Met., 7 (1978), 145.

11) J. R. Low, Jr.: Fracture of Engineering Materials, ASM, (1964), 127.

12) T. Wada and W. G. Hagel: Met. Trans. A, 7A (1976), 1419

13) T. Wada and D. V. Doane: Met. Trans., 5 (1974), 231.

14) A. H. Ucisik, G. J. McMahon, Jr. and H. G. Feng: Met . Trans., 9A (1978), 321.

15) J. R. Mellic and C.J. McMahon, Jr.: Met. Trans., 5 (1974), 516.

16) T. Ogura, G. J. McMahon, Jr., H. C. Feng and V. Vitek: Acta Met., 26 (1978), 1317.

17) C. S. Smith: Trans. ASM, 45 (1953), 533.

18) R.W.K. Honeycombe and F. B. Pickering: Met. Trans., 3 (1972), 1099.

19) C. W. Marschall, R. F. Heheman and A. R. Troiano: Trans. ASM, 55 (1962), 135.

20) K. J. Kim and L. H. Schwartz: Mat. Sci. Eng., 33 (1978), 5.

21) G. R. Irwin: Proc. 7th Sagamore Conf., Syracuse Univ. Press, New York, (1960), IV-63.

22) K. Nagai, Y. Ujiie, K. Shibata and T. Fujita: Trans. ISIJ, 22 (1982), 696.

23) K. Nagai, K. Shibata, M. Murakami and T. Fujita: Tetsuto-Hagané, 69 (1983), 462. 